\title{
www.waavp2011-argentina.com.ar
}




\section{In vitro efficacy of plant extracts and synthesized substances on Rhipicephalus (Boophilus) microplus (Acari: Ixodidae)}

\footnotetext{
L. D. de Barros ${ }^{1}$, A. C. de Souza Chagas ${ }^{2}$, F. Cotinguiba ${ }^{3}$, M. Furlan ${ }^{3}$, R. Giglioti ${ }^{1}$, M. C. de Sena Oliveira ${ }^{2}$, H. Ribeiro Bizzo ${ }^{4}$ ${ }^{1}$ Faculdade de Ciências Agrárias e Veterinárias/UNESP, Jaboticabal, SP; ${ }^{2}$ Centro de Pesquisa Pecuária Sudeste/EMBRAPA, São Carlos, SP; ${ }^{3}$ Instituto de Química/UNESP, Araraquara, SP; ${ }^{4}$ Centro de Tecnologia Agroindustrial de Alimentos/EMBRAPA, Rio de Janeiro, RJ.

Herbal drugs have been widely evaluated as an alternative method of parasite control, aiming to slow development of resistance and obtain low-cost biodegradable parasiticides. The aim of this study was to evaluate the in vitro efficacy on Rhipicephalus (Boophilus) microplus of Carapa guianensis, Cymbopogon martinii, Cymbopogon schoenanthus and Piper tuberculatum extracts and similar synthesized substances. In the immersion test, engorged females were collected from cattle and evaluated in five dilutions ranging from $10 \%$ to $0.030625 \%$. In the larval test, around 100 larvae were placed on filter paper impregnated with the dilutions, ranging from $10 \%$ to $0.02 \%$. The treatments and controls in both tests were done in three replicates. Phytochemical analysis of oils was performed by gas chromatography. The main compounds were oleic acid $(46.8 \%)$ for $C$. guianensis and geraniol for C. martinii (81.4\%) and C. schoenanthus (62.5\%). The isolated and synthesized substances showed no significant effect on larvae and engorged females. C. martinii at a concentration of $5 \%$ and $P$. tuberculatum at $10 \%$, showed the best efficacy on the engorged females, causing $75.60 \%$ and $91.97 \%$ mortality, respectively. The fact that geraniol is present in greater quantities in C. martinii explains its higher activity in relation to $C$. shoenanthus. There is still a need to validate the in vivo use of safe and effective phytoparasiticidal substances. Efforts should be focused on developing formulations that enhance the efficacy of these extracts in vivo and lengthen the residual period.
} 